(RESEARCH ARTICLE)

\title{
Evaluation of subdermal implants among family planning acceptors in a tertiary hospital, Nigeria
}

\author{
Nonye-Enyidah Esther Ijeoma ${ }^{1,{ }^{*}}$ and Enyidah Nonyenim Solomon 2 \\ ${ }^{1}$ Department of Obstetrics and Gynaecology, Rivers State University Teaching Hospital, Port Harcourt, Rivers State, \\ Nigeria. \\ ${ }^{2}$ Department of Medicine, Rivers State University Teaching Hospital, Port Harcourt, Rivers State, Nigeria.
}

Publication history: Received on 15 November 2020; revised on 24 November 2020; accepted on 25 November 2020

Article DOI: https://doi.org/10.30574/wjarr.2020.8.2.0434

\begin{abstract}
Background: Subdermal contraceptive implants are safe, convenient, very effective and reversible. Though they have numerous benefits, their use is still discontinued due to various reasons including side effects in the body of acceptors.

Objective: To determine and compare the prevalence rates, side effects, discontinuation rates and indications for discontinuation of two subdermal implants (Jadelle and Implanon) at Rivers State University Teaching Hospital (RSUTH), Port Harcourt, Nigeria.

Methods: A retrospective study of 874 clients attending family planning clinic at the RSUTH from $1^{\text {st } J a n u a r y, ~} 2015$ $31^{\text {st }}$ December, 2019 was conducted. Their records were retrieved from the clinic and reviewed. Data was extracted, coded and analyzed using the statistical package for social sciences (SPSS) IBM version 25.0 (Armonk, NY).

Result: Four hundred and twenty five women used subdermal implants out of 874 acceptors of contraceptives within the study period giving an uptake rate of $48.6 \%$. Implanon was more preferred accounting for $66.6 \%$ and Jadelle $33.4 \%$. The mean age was $33.24 \pm 4.13$ years. Most age group was $30-34$ years accounting for $51.3 \%$. Age range was $20-48$ years and most (80\%) were multiparous. Most (99.1\%) were Christians and $98.4 \%$ were married. Only one client $(0.2 \%)$ had no formal education. Seventy three (26.4\%) acceptors discontinued the use. Most were due to desire for pregnancy (46.4\%) and menorrhagia (24.1\%). Four unintended pregnancies occurred giving a Pearl index of 0.9.
\end{abstract}

Conclusion: Subdermal implants are safe and effective. Menstrual abnormality and desire for pregnancy were the commonest reasons for discontinuation.

Keywords: Subdermal Implants; Prevalence Rate; Side Effects; Discontinuation Rate; RSUTH.

\section{Introduction}

Contraceptive implants are progesterone only contraception inserted subdermally in the non-dominant upper arm by trained providers. They are long term, safe and very effective contraceptives with few side effects that pose no risk to the health of the acceptors.The reported use pregnancy rate is $0.05 \%$ [1-3]. They are readily reversible with a return to fertility within days of removal. Female implants include Norplant, Norplant-2 (Jadelle), Implanon, Nexplanon and Capronor. They differ based on the progestin content and whether they are degradable or not [2]. Norplant and Jadelle contain levonorgestrel which is a second generation progestin whereas implanon and Nexplanon contain etonorgestrel, a third generation progestin.

*Corresponding author: Nonye-Enyidah Esther Ijeoma

Department of Obstetrics and Gynaecology, Rivers State University Teaching Hospital, Port Harcourt, Rivers State, Nigeria. 
Jadelle was approved by the United States Food and Drug Administration (USFDA) in 1996 and consists of two rods $(2.5 \mathrm{~mm}$ by $43 \mathrm{~mm})$ each containing $75 \mathrm{mg}$ of levonorgestrel. It is licensed for 5 years. Implanon was introduced in 1998 and was approved by USFDA in 2006. It consists of a single rod ( $2 \mathrm{~mm}$ by $40 \mathrm{~mm}$ ) containing $68 \mathrm{mg}$ etonorgestrel and it is licensed for 3 years. The primary mode of action is to prevent ovulation. Secondary modes of action include prevention of sperm penetration of the cervical mucus and implantation by thinning of the endometrium [4-7].

The major side effect associated with the use of implants is a change in bleeding pattern (frequency, duration and amount). Other side effects are weight gain, headaches, abdominal pain, waist pain, acne, dizziness, nausea, breast tenderness, neurovascular injury and mood changes. It also includes complications related to insertion like pain, slight bleeding, hematoma, skin atrophy and breakage of implant during removal. Rarely ovarian cyst and infection at the site of implant may occur $[2,7,8]$. Depending on the severity of these complications, they may cause discontinuation of the implants. The side effects, use effectiveness, discontinuation rate and reasons for discontinuation of subdermal implants in RSUTH, Port Harcourt have not been evaluated since the inception of the family planning clinic; thus the need for this study.

\section{Materials and methods}

A retrospective comparative study carried out at the family planning clinic of the RSUTH in Port-Harcourt, the capital of Rivers State in southern Nigeria.

The clinic gets its clients from within Port Harcourt and its environment. The clinic is headed by a consultant Gynaecologist, with the support of trained family planning nurses and resident doctors.

After counseling by the family planning nurses and physicians, the clients were allowed to make informed choice based on their needs and available contraceptives suitable for them. Thereafter medical history and clinical examination were done to exclude contraindications to the use of subdermal contraceptive implants. Urine analysis and pregnancy test were also done for the clients and informed consent obtained. During the study period, the only available subdermal implants were jadelle and implanon. The nurses inserted one or two rods of implanon or jadelle respectively 8-10cm above the medial epicondyle of the humerus subdermally, to avoid the risk of neurovascular damage at insertion and removal. The insertion was done within 7 days of normal menstrual period after excluding pregnancy. They were also inserted within 21 days post-partum in breastfeeding mothers who were yet to resume menstruation. Following insertion, the service provider confirmed the presence of the implant by palpation and also asked the client to do so. Thereafter the procedure was documented including the arm the implant has been inserted into and that it was felt. The date of the removal of the implants was also documented. Follow up observations were done.

At each visit, the client's complaints were documented and appropriate treatment given. The weight, blood pressure and results of urinalysis were also noted. The record cards of all the clients that accepted subdermal implants between $1^{\text {st }}$ January, 2015 and $31^{\text {st }}$ December, 2019 were retrieved and studied. The information extracted from the cards included the socio-demographic characteristics of the clients, side effects and complaints, discontinuation and the reasons for discontinuation of the contraceptives, previous contraceptives used and their sources. Also any unintended pregnancy following the use of subdermal implants was also documented in the cards. The data was analyzed with the statistical package for social sciences (SPSS) IBM version 25.0 (Armonk, NY) using frequency counts and percentages. Chi square test was used as test of significance where applicable and a $P$-value $<0.05$ was considered statistically significant. Level of confidence interval was set at $95 \%$.

\section{Results}

Four hundred and twenty five (425) clients accepted and used subdermal contraceptive implants during the study period, accounting for $48.6 \%$ of the 874 contraceptive acceptors. Of the 425 acceptors, 142 (33.4\%) chose jadelle and $283(66.6 \%)$ chose implanon. This makes implanon a more preferred implant as shown in figure 1 . There were 4 unintended pregnancies, two each occurred during the use of implanon and jadelle respectively. One of the accidental pregnancies that occurred during the use of implanon was an ectopic pregnancy. The age range of the acceptors was 20-48 years. The mean age \pm SD for implant acceptors was 33.2 \pm 4.1 years. The mean age \pm SD of the acceptors of jadelle was $32.9 \pm 4.2$ years compared to $33.4 \pm 4.1$ years for implanon. The parity range was 0 to 9 and the modal parity of the two contraceptives was para 3. The socio-demographic profile of the acceptors of the implants is shown in table 1 . The modal age group was 30-34 years accounting for 218 (51.3\%) clients. Most of the women, 340 (80\%) were multipara and married women accounted for $418(98.4 \%)$ of the clients. Four hundred and twenty one (99.1\%) acceptors were Christians while 424 (99.8\%) had formal education. Most of the clients, 236 (55.5\%) had tertiary level of education. Of 
the socio-demographic characteristics of the acceptors of subdermal implants, age $\left(\mathrm{X}^{2}=41.42, P=0.02\right)$ was the only parameter statistically significant as shown in table 1.

Table 1 Socio-demographic characteristics of the clients

\begin{tabular}{|c|c|c|c|c|c|}
\hline Variable & Jadelle & Implanon & Subdermal Implants & $\mathrm{X}^{2}$ & P-value \\
\hline & No & No & Total no. (\%) & & \\
\hline \multicolumn{6}{|l|}{ Age } \\
\hline $\begin{array}{l}20-24 \\
25-29 \\
30-34 \\
35-39 \\
40-44 \\
45-49\end{array}$ & $\begin{array}{l}2 \\
18 \\
82 \\
32 \\
5 \\
3\end{array}$ & $\begin{array}{l}3 \\
38 \\
136 \\
82 \\
24 \\
0\end{array}$ & $\begin{array}{ll}5 & (1.2) \\
56 & (13.2) \\
218 & (51.3) \\
114 & (26.8) \\
29 & (6.8) \\
3 & (0.7)\end{array}$ & 41.42 & $0.02^{*}$ \\
\hline \multicolumn{6}{|l|}{ Educational Status } \\
\hline $\begin{array}{l}\text { No formal education } \\
\text { Primary } \\
\text { Secondary } \\
\text { Tertiary }\end{array}$ & $\begin{array}{l}0 \\
5 \\
54 \\
83\end{array}$ & $\begin{array}{l}1 \\
6 \\
123 \\
153\end{array}$ & $\begin{array}{l}1(0.2) \\
11(2.6) \\
177(41.7) \\
236(55.5)\end{array}$ & 2.22 & 0.53 \\
\hline \multicolumn{6}{|l|}{ Religion } \\
\hline $\begin{array}{l}\text { Christianity } \\
\text { Islam }\end{array}$ & $\begin{array}{l}141 \\
1\end{array}$ & $\begin{array}{l}280 \\
3\end{array}$ & $\begin{array}{l}421(99.1) \\
4(0.9)\end{array}$ & 0.13 & 0.72 \\
\hline \multicolumn{6}{|l|}{ Parity } \\
\hline $\begin{array}{l}\text { Nullipara } \\
\text { Primipara } \\
\text { Multipara } \\
\text { Grand- multipara }\end{array}$ & $\begin{array}{l}1 \\
12 \\
116 \\
13\end{array}$ & $\begin{array}{l}3 \\
18 \\
224 \\
38\end{array}$ & $\begin{array}{l}4 \quad(0.9) \\
30(7.1) \\
340(80.0) \\
51(12.0)\end{array}$ & 8.68 & 0.37 \\
\hline \multicolumn{6}{|l|}{ Marital Status } \\
\hline $\begin{array}{l}\text { Single } \\
\text { Married }\end{array}$ & $\begin{array}{l}1 \\
141\end{array}$ & $\begin{array}{l}6 \\
277\end{array}$ & $\begin{array}{l}7(1.6) \\
418(98.4)\end{array}$ & 1.17 & 0.28 \\
\hline
\end{tabular}

Figures $2 \mathrm{a}$ and $2 \mathrm{~b}$ show the sources of previous contraceptives used by the clients. One hundred and forty-eight (34.8\%) clients got their previous contraceptives from government owned hospitals, 66 (15.5\%) got theirs from private hospitals and $211(49.7 \%)$ did not use any form of contraceptives. Most of the clients 185 (43.5\%) did not use any method of contraception prior to the use of subdermal implants, $56(13.2 \%)$ previously used barrier method, 47 (11.1\%) used implants and $40(9.4 \%)$ used oral contraceptive pills (OCPs). Others were injectable 25 (5.9\%), IUCD 25 (5.9\%), Postinor 21 (4.9\%), withdrawal method $14(3.3 \%)$ and Calendar method $12(2.8 \%)$. This is shown in table 2.

Side effects associated with the use of subdermal contraceptive implants which also contributed to the reasons for discontinuation of this contraceptive method are shown in table 3. Eighty-one (81) and one hundred and eighty-four (184) clients who used jadelle and implanon respectively had no complaints. Hence 265 (62.4\%) out of 425 clients did not have side effects and complaints. One hundred and sixty (37.6\%) women had side effects and complaints which include menorrhagia 56 (35\%), irregular vaginal bleeding 43 (26.9\%), amenorrhoea 30 (18.8\%), headache 14 (8.7\%), 
lower abdominal pain and waist pain $8(5 \%)$. Others included weight gain $6(3.7 \%)$, chest pain $2(1.3 \%)$ and sexual dysfunction $1(0.6 \%)$.

Discontinuation rate is shown in figure 3. One hundred and twelve (26.4\%) clients discontinued the contraceptives, 73 (65.2\%) from implanon and 39 (34.8\%) for jadelle. Of the 112 clients that discontinued the use of the implants, 27 $(24.1 \%)$ had menorrhagia, 10 (8.9\%) had irregular vaginal bleeding, $6(5.3 \%)$ complained of headache and weight gain, lower abdominal pain and waist pain contributed $4(3.6 \%)$ respectively. Others discontinued the use of implants due to breast cancer, menopause, chest pain, sexual dysfunction and husband's request. Fifty-two (46.4\%) women desired to get pregnant and there were 4 unintended pregnancies giving a Pearl pregnancy rate of 0.9 per 100 women years. The reasons for discontinuation of subdermal implants are shown in table 4.

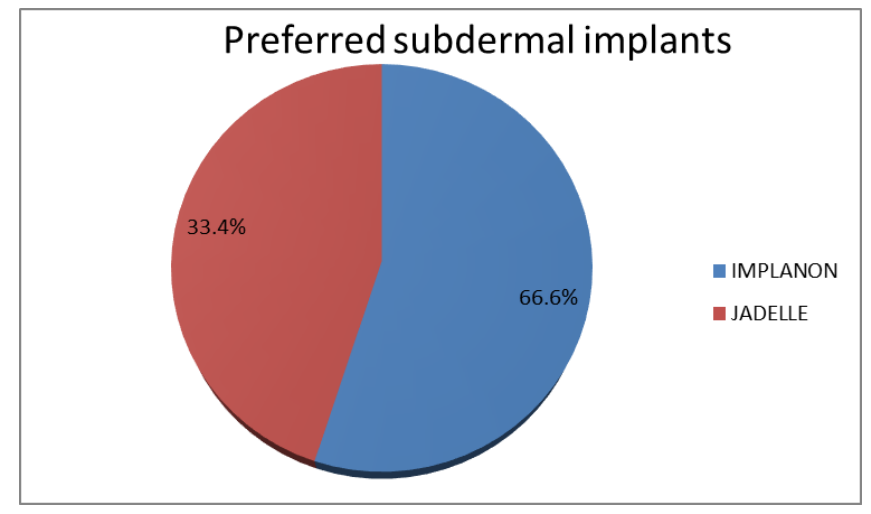

Figure 1 Preferred subdermal contraceptive implants

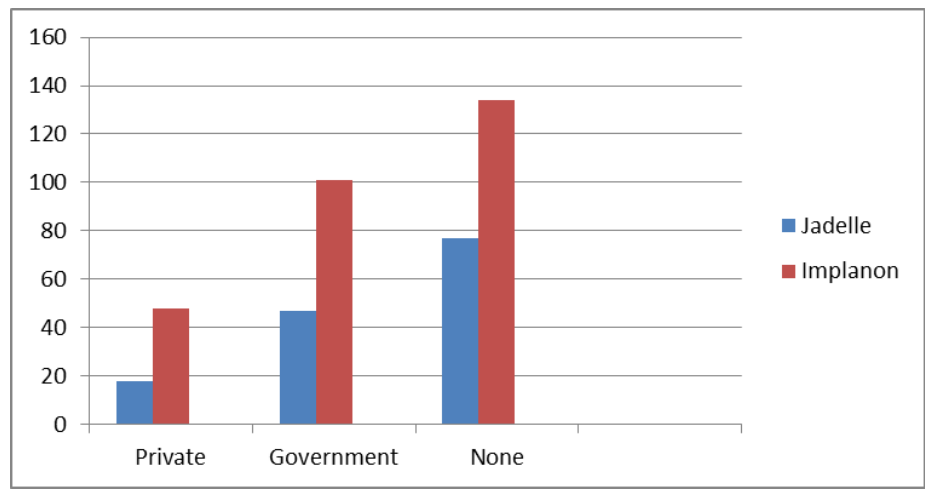

Figure 2a Sources of previous contraceptives used by clients.

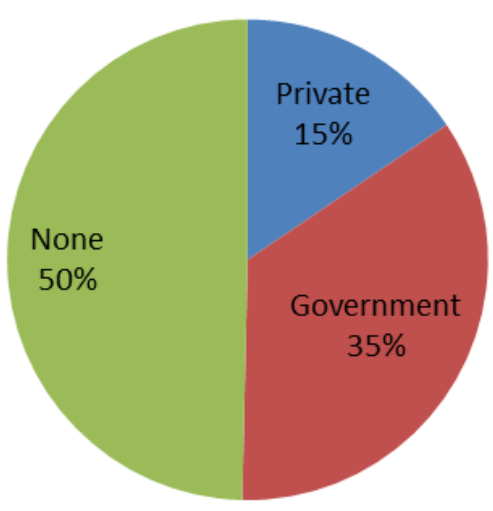

Figure $\mathbf{2 b}$ Sources of previous contraceptives used by clients for both contraceptives. 
Table 2 Previously used contraceptives by the clients

\begin{tabular}{|l|l|l|l|l|}
\hline \multirow{2}{*}{ Methods } & \multicolumn{2}{|c|}{ Frequency } & \multirow{2}{*}{ Percentage } \\
\cline { 2 - 4 } & Jadelle $(\mathrm{n}=142)$ & Implanon $(\mathrm{n}=283)$ & Total $(\mathrm{n}=425)$ & \\
\hline Calendar & 4 & 8 & 12 & 2.8 \\
\hline Postinor & 5 & 16 & 21 & 4.9 \\
\hline Withdrawal & 6 & 8 & 14 & 3.3 \\
\hline Implant & 8 & 39 & 47 & 11.1 \\
\hline Injectable & 8 & 17 & 25 & 5.9 \\
\hline IUCD & 9 & 16 & 25 & 5.9 \\
\hline OCPs & 15 & 25 & 40 & 9.4 \\
\hline Barrier & 19 & 37 & 56 & 13.2 \\
\hline No method & 68 & 117 & 185 & 43.5 \\
\hline
\end{tabular}

Table 3 Side effects of subdermal implants

\begin{tabular}{|l|l|l|l|l|}
\hline \multirow{2}{*}{ Side effects } & \multicolumn{2}{l}{ Frequency } & \multirow{2}{*}{ Percentage } \\
\cline { 2 - 4 } & $\begin{array}{l}\text { Jadelle } \\
(\mathrm{n}=61)\end{array}$ & $\begin{array}{l}\text { Implanon } \\
(\mathrm{n}=99)\end{array}$ & $\begin{array}{l}\text { Total } \\
(\mathrm{n}=160)\end{array}$ & \\
\hline Menorrhagia & 21 & 35 & 56 & 35.0 \\
\hline Irregular vaginal bleeding & 16 & 27 & 43 & 26.9 \\
\hline Amenorrhoea & 13 & 17 & 30 & 18.8 \\
\hline Headache & 7 & 7 & 14 & 8.7 \\
\hline Weight gain & 3 & 3 & 6 & 3.7 \\
\hline LAP and waist pain & 1 & 7 & 8 & 5.0 \\
\hline Chest pain & 0 & 2 & 2 & 1.3 \\
\hline $\begin{array}{l}\text { Sexual dysfunction (vaginal dryness and reduced } \\
\text { libido) }\end{array}$ & 0 & 1 & 1 & 0.6 \\
\hline
\end{tabular}

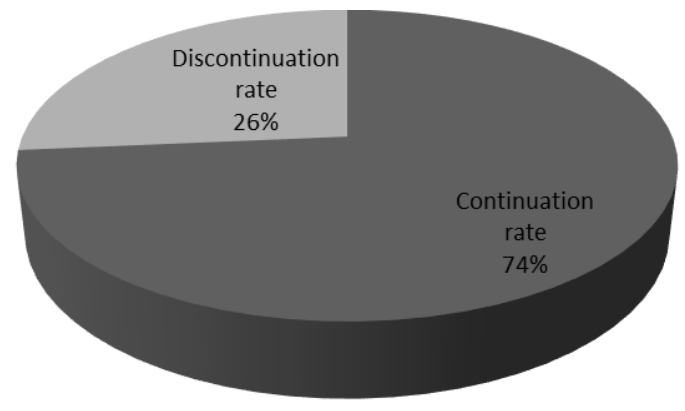


Figure 3 Continuation and discontinuation rates of subdermal implants

Table 4 Reasons for discontinuation of subdermal implants

\begin{tabular}{|l|l|l|l|l|}
\hline \multirow{2}{*}{ Side effects } & \multicolumn{3}{|c|}{ Frequency } & \multirow{2}{*}{ Percentage } \\
\cline { 2 - 5 } & $\begin{array}{l}\text { Jadelle } \\
(\mathrm{n}=39)\end{array}$ & $\begin{array}{l}\text { Implanon } \\
(\mathrm{n}=73)\end{array}$ & $\begin{array}{l}\text { Total } \\
(\mathrm{n}=112)\end{array}$ & \\
\hline Menorrhagia & 13 & 14 & 27 & 24.1 \\
\hline Desire for pregnancy & 9 & 43 & 52 & 46.4 \\
\hline Irregular vaginal bleeding & 7 & 3 & 10 & 8.9 \\
\hline Headache & 3 & 3 & 6 & 5.3 \\
\hline Weight gain & 2 & 2 & 4 & 3.6 \\
\hline Pregnancy & 2 & 2 & 4 & 3.6 \\
\hline LAP and waist pain & 1 & 3 & 4 & 3.6 \\
\hline Breast cancer & 1 & 0 & 1 & 0.9 \\
\hline Menopause & 1 & 0 & 1 & 0.9 \\
\hline Husband's request & 0 & 1 & 1 & 0.9 \\
\hline Chest pain & 0 & 1 & 1 & 0.9 \\
\hline $\begin{array}{l}\text { Sexual dysfunction (vaginal dryness } \\
\text { and reduced libido) }\end{array}$ & 0 & 1 & 1 & 0.9 \\
\hline & \multicolumn{2}{|l|}{ LAP= Lower abdominal pains } & \\
\hline
\end{tabular}

\section{Discussion}

The uptake rate of subdermal contraceptive implants during the study period is $48.6 \%$ which is quite impressive and encouraging compared to $29.6 \%$ from a previous similar study [9]. This $48.6 \%$ is higher than $31.9 \%$ from Abakiliki [5], $18.6 \%$ from Uyo [10] but lower than $55.8 \%$ in Sokoto [11]. The higher prevalence rate noted in this study and that from Sokoto may be due to increase in awareness of these implants compared to the earlier studies done when the implants were newly introduced in Nigeria.Also the level of education and their effectiveness have been adduced for this increase [12]. Three women had unintended intrauterine pregnancy and one had an ectopic gestation during the study period; giving a Pearl index of 0.9. This is unlike the previous studies where there was no accidental pregnancy recorded $[5,9,10,13]$. A further review of these four clients may reveal why the pregnancies occurred. The index of 0.9 is also in line with the annual pregnancy rates of less than 1 with all implants [3]. There is no significant difference in pregnancy rates between etonorgestrel and levonorgestrel implants [14].

Jadelle and implanon were the two subdermal implants available at the family planning clinic of RSUTH during the study period. The number of acceptors of implanon was more than those that accepted jadelle. This might be due to the one rod of implanon compared to two rods of jadelle which are regarded as foreign bodies. This finding is similar to findings by Nonye-Enydah et al and Adeyemi et al; unlike other studies where jadelle was more preferred $[5,10]$. Subdermal implants acceptors were between the ages of 20 and 48 years with mean age \pm SD of 33.2 \pm 4.1 years and most were in $30-34$ years age group. This is similar to other studies $[5,9,10,13]$. There were no adolescents that accepted implants in this study in keeping with results from other studies $[15,16]$. This poor acceptance rate by the teenagers could be that they patronize the chemist shops as they probably would not want to be identified by the service providers as being sexually active.

More than $99 \%$ of the acceptors in this study had formal education. This is expected as studies have shown that formal education significantly increases the use of contraceptives [17]. Most of the acceptors were multipara and married. The women chose this method of contraception to either limit or space childbirth. Those that have completed their family size and the grandmultipara prefer the subdermal implants to bilateral tubal ligation as there is aversion to the later in our environment due to cultural and religious beliefs. This is in keeping with other studies $[9,10]$. Most of the clients were Christians because majority of the population in southern Nigeria are Christians. 
The only socio-demographic characteristics of the acceptors of implanon and jadelle found to be statistically significant is age $(P=0.02)$. This finding is similar to a previous study [9] although both age and parity were statistically different in the previous study. Older women were more likely to use the contraceptives than younger age group. The study revealed no statistically significant effect of educational status $(P=0.53)$, religion $(P=0.72)$, parity $(P=0.37)$ and marital status $(P=0.28)$ on the use of both implanon and jadelle.

Sixty-two percent of the clients had no side effects and complaints indicating a good safety profile of the contraceptives. Menstrual disorders were the commonest complications experienced by the clients with most of them having menorrhagia and irregular vaginal bleeding especially few months after insertion; and secondary amenorrhoea. This is in keeping with results of several studies $[4,10,18]$. These menstrual disorders are due to the effect on ovarian function. Fluctuating endogenous production from irregular follicular growth leads to irregular bleeding whereas secondary amenorrhoea has been attributed to ovarian suppression and endometrial atrophy [7]. Secondary amenorrhoea may be beneficial to some women especially those that require reduced menstrual flow and those with sickle cell anaemia. The weight gain may be due to improved appetite leading to increase in food intake. The injectables have also been found to cause slight water retention contributing to this weight gain [19]. About 50-60\% of implants users have been documented to report irregular vaginal bleeding patterns during the first year of use; however, it resolves spontaneously in subsequent years of use [20]. Therefore pre insertion counseling and proper documentation in the client's cards about the menstrual disturbances to expect, is important to increase the continuation rates, since the noncontraceptive benefits outweighs the side effects. [10,20,21].

The discontinuation rates of contraceptives vary by region, country and method of contraception [22]. The discontinuation rate of subdermal implants in this study was $26.4 \%$. This is higher than $17.6 \%, 12.5 \%$ and $1.02 \%$ recorded by Adeyemi AS et al, Igwe NM et al and Abasiattai AM et al respectively [510,13].The commonest reason for discontinuation which accounted for $46.4 \%$ was desire for pregnancy. This is followed by menstrual abnormalities accounting for $33 \%$. This is similar to findings by Igwe NM et al and AdeyemiAS et al where desire for pregnancy accounted for $68.1 \%$ and $80 \%$ of discontinuation rates respectively $[5,13]$.

One client attained menopause and discontinued the use, another client discovered she had breast cancer and discontinued the use also. Lastly one acceptor stopped using implanon on husband's request. This shows how men can influence the use of contraceptives and the need to include them during counseling and choice of any method of contraception.

\section{Conclusion}

Subdermal contraceptive implants are very effective, safe and used mainly by young, educated, married and multiparous women. Implanon was more popular than jadelle. Clients' age was the only socio-demographic factor found to have effect on the use of both contraceptives. Menstrual disorders remain the major side effects of these contraceptives and could lead to discontinuation. Continuation rate was good and desire for pregnancy was the commonest reason for discontinuation. Therefore, adequate counseling before and during follow up visits will go a long way in reducing the discontinuation rate of this method of contraception.

\section{Compliance with ethical standards}

\section{Acknowledgments}

We are grateful to the staff of the family planning clinic for the assistance rendered for this study.

\section{Disclosure of conflict of interest}

Authors have declared that no competing interests exist.

\section{Statement of ethical approval}

Ethical approval was given by the Hospital's Ethics committee.

\section{References}

[1] ACOG Practice Bulletin. Long-acting reversible contraception: Implants and intrauterine devices. Clinical management guidelines for obstetrician-gynecologists 2011. 
[2] Kolawale 00, Sowemimo 00, Ojo 00, Fasubaa OB. Contraceptive implants: A review and current perspective in southwest Nigeria. Tropical Journal of Obstetrics and Gynaecology, 2018; 35 (2):108-112.

[3] Steiner M, Lopez M, Grimes D, et al. Sino-implant (II)—a levonorgestrel-releasing two-rod implant: systematic review of the randomized controlled trials. Contraception. 2010; 81(3):197- 201.

[4] Rowlands S, Searle S. Contraceptive implants: Current perspectives. Open Access J Contraception 2014; 5:73-84.

[5] Igwe NW, Nnamdi EB, Jude AJ. A 5-year clinical evaluation of subdermal implants among abakaliki acceptors. J Basic ClinReprodSci, 2016; 5:1-5.

[6] Mansour D. Nexplanon®: what Implanon® did next. Journal of Family Planning and Reproductive Health Care. 2010; $36(4): 187$.

[7] Burkman R and Amnon B. Contraception and Family Planning. In: Decheney AH (Ed.). Current Diagnosis and Treatment Obstetrics and Gynaecology, Lange Medical Book, McGraw-Hill Companies, New York, 2013; 928-947.

[8] World Health Organization Department of Reproductive Health and Research (WHO/RHR) and Johns Hopkins Bloomberg School of Public Health/Center for Communication Programs (CCP). Family Planning: A Global Handbook for Providers. Baltimore and Geneva: CCP and WHO; 2011.

[9] Nonye-Enyidah EI, Wekere FCC, Enyidah NS. Comparison of two subdermal contraceptive implants in a tertiary hospital in southern Nigeria. European Journal of Research in Medical Sciences, 2020; 8 (1):47-54.

[10] Abasiattai AM, Utuk NM, Inyang-Etoh EC. Subdermal contraceptive implants: Profile of acceptors in a tertiary hospital in Southern Nigeria. Int J GynaecolObstet Neonatal Care, 2014; 1:9-13.

[11] Shehu CE, Burodo AT. Contraceptive choices among women attending the fertility research unit of UsmanuDanfodiyo University Teaching Hospital, Sokoto. Sahel Med J 2013; 16:93.

[12] Ohihoin GA, Bello B, Herbertson EC, Ezechi OC. Use of modern contraceptive implants the: Lagos island maternity Hospital experience. Trop J ObstetGynaecol, 2015; 32:125-31.

[13] Adeyemi AS, Owonikoko KM, Adekanle DA, Aworinde O. Subdermal contraceptive implants: Experience at a tertiary health institution in southwestern Nigeria. Sahel Medical Journal, 2018; 21:137-40.

[14] Power J, French R, Cowan FM. Subdermal implantable contraceptives versus other forms of reversible contraceptives or other implants as effective methods for preventing pregnancy. Cochrane Database Syst Rev 2007; 3:CD001326.

[15] Mastor A, Khaing SL, Oman SZ. User's perspective on implanon in Malaysia: a multicultural perspective Asian country. Open Access J Contraception 2011; 2:79-84.

[16] Bhatia P, Nangia S, Aggarwal S, Tewari C. Implanon: Subdermal single rod contraceptive implants. J ObstetGynaecol India, 2011; 61(4):422-425.

[17] National Population Commission, ICF International. Nigeria Demographic and Health Survey 2013. Abuja, Nigeria and Rockville, Maryland, USA: NPC and ICF International, 2014; 97.

[18] Ali M, Akin A, Bahamondes L, Brache V. et al. Extended use up to 5 years of the etonogestrel-releasing subdermal contraceptive implant: comparison to levonorgestrel-releasing subdermal implant. Human Reproduction, 2016; 31 (11):2491-2498.

[19] Oshodi YA, Agbara JO, Ade-Fashola 00, Akinlusi FM, Olalere HF, Kuye TO. Weight gain and menstrual abnormalities between users of Depo-provera and Noristerat. International Journal of Repro.ContraceptObstetGynaecol, 2019; 8 (6):2226-2231.

[20] Olotu E, Mascarenhas L. Subdermal contraceptive implants. Br J FamPlann 2000; 26 (3):171-179.

[21] Grimes DA. Forgettable contraception. Contraception. 2009; 80 (6):497-499.

[22] Barden-O'Fallon J, Speizer IS, Carroon M. Womens's contraceptive discontinuation and switching behaviour in urban Senegal, 2010-2015. BMC Women's Health, 2018; 18 (1):35. http://doi.org/10.1186/s12905-018-05299. 